\title{
In vitro maintenance of boar sperm viability by a soluble fraction obtained from oviductal apical plasma membrane preparations
}

\author{
A. Fazeli ${ }^{1}$, R. M. A. Elliott ${ }^{2}$, A. E. Duncan ${ }^{3}$, A. Moore², P. F. Watson ${ }^{3}$ \\ and W. V. Holt ${ }^{2}$ \\ ${ }^{1}$ Academic Unit of Reproductive and Developmental Medicine, The University of Sheffield, Level 4, The \\ Jessop Wing, Tree Root Walk, Sheffield S10 2SF, UK; ${ }^{2}$ Institute of Zoology, Regent's Park, London \\ NW1 4RY, UK; and ${ }^{3}$ The Royal Veterinary College, Royal College Street, London NW1 OTU, UK
}

Oviductal apical plasma membrane fractions have been successfully used to provide an in vitro model to study the role of direct membrane contact in sperm-oviduct interactions. Apical plasma membrane preparations from pig oviductal tissues show a dose-response in their ability to maintain boar sperm viability in vitro. Membrane preparations obtained from other tissues (lung and duodenum) are incapable of maintaining boar sperm viability to the same extent as oviductal tissue. The present study examined the validity of two hypotheses that arise from current knowledge of sperm-oviduct interactions, namely, that (i) apical plasma membranes prepared from ampullar regions of the oviduct are less effective than those from isthmus regions, and (ii) sperm survival is more effective in apical plasma membrane preparations derived from follicular phase oviducts than those derived from luteal phase oviducts. Both hypotheses were proved false. The nature of the active component(s) in the oviductal apical plasma membrane fractions was further investigated. Heat treatment $\left(100^{\circ} \mathrm{C}\right.$ for $\left.20 \mathrm{~min}\right)$ diminished the capacity of membranes to support boar sperm viability. Furthermore, a soluble salt-extracted fraction obtained from oviductal apical plasma membrane preparations was biologically active and supported boar sperm viability in vitro. This may indicate that the active factor(s) responsible for the maintenance of boar sperm viability is not an integral part of oviductal membranes and is peripherally bound to these membranes.

\section{Introduction}

After mating, inseminated mammalian spermatozoa are transported to the oviduct where a reservoir of spermatozoa is formed. Studies in several species have shown that the reservoir is limited to the caudal isthmus (Hunter, 1981, 1984; Hunter and Nichol, 1983; Smith and Yanagimachi, 1990), where spermatozoa are held until ovulation, when a small number is released to meet the egg(s) (Hunter, 1984; Suarez, 1987; Smith and Yanagimachi, 1991). During storage in the isthmus, many spermatozoa attach to the oviductal epithelial cells (Motta and Van Blerkom, 1975; Flechon and Hunter, 1981; Smith et al., 1987; Hunter et al., 1991). Attachment to oviductal epithelial cells is important in maintaining sperm viability both in vivo (Smith and Yanagimachi, 1990) and in vitro (Pollard et al., 1991; Suarez et al., 1991; Ellington et al., 1993). Sperm attachment to oviductal epithelial cells is initiated by uncapacitated spermatozoa (Fazeli et al., 1999) and it appears that carbohydrates are involved in mediating the

Email: a.fazeli@Sheffield.ac.uk attachment process (DeMott et al., 1995; Green et al., 2001). The process of capacitation, together with the switch to the hyperactivated flagellar beating pattern (Yanagimachi, 1994), appears to coincide with the ability of spermatozoa to be released from the oviductal reservoir.

Despite the importance of direct membrane contact between oviduct epithelia and spermatozoa, and the possible involvement of oviductal membrane proteins in this interaction, many studies in the past have only investigated the role of oviductal secretory products (proteins) on spermatozoa. This is partially related to the ease of obtaining oviduct secretory products from in vivo (McNutt et al., 1994; Lapointe and Sirard, 1996; Kawakami et al., 1998, 2000; Rodriguez and Killian, 1998) and in vitro sources (Ijaz et al., 1994; Abe et al., 1995a,b; Lapointe and Sirard, 1998; Martus et al., 1998). Until recently there was no experimental protocol to determine the role of direct membrane contacts between spermatozoa and oviductal epithelial cells. In nearly all experimental models (epithelial monolayers or explants), spermatozoa were in contact with the oviductal cells and simultaneously exposed to oviductal 
secretions. However, Smith and Nothnick (1997) reported a simple technique based on differential precipitation of membranes for the isolation of apical plasma membrane (APM) fractions from rabbit oviducts. This technique provided the first in vitro model for studying interactions between spermatozoa and oviductal APM without the interference of oviduct secretions. Incubation of rabbit spermatozoa with oviductal APM prepared using this methodology prolongs sperm viability in vitro (Smith and Nothnick, 1997). In a similar way, preparations of APM isolated from mare isthmic oviductal epithelium prolong viability, delay capacitation and maintain low $\left[\mathrm{Ca}^{2+}\right]_{i}$ in stallion spermatozoa (Dobrinski et al., 1997). However, co-incubating rabbit spermatozoa with kidney APM does not improve sperm longevity (Smith and Nothnick, 1997). This finding implies that the biologically relevant activity seems to be specific to APM obtained from reproductive tissue. These results collectively emphasize the role that direct membrane contact may play in sperm-oviductal epithelial cell interaction and indicate that the mechanism is conserved among different mammalian species.

The aim of the current investigation was to investigate the role that components of isolated APM fractions may play in sperm-oviduct interactions. This study investigated the dose-response effect of these membranes on the maintenance of boar sperm viability in vitro and determined whether the specificity of this effect is limited to APM obtained from reproductive tissue. The current dogma implies that the sperm reservoir in female pigs is limited to the isthmic region of the oviduct and this in turn indicates that the sperm viability maintenance effect of APM preparations is limited to spermatozoa obtained from the isthmic region. In a similar way, as spermatozoa are not required to survive during the luteal phase of the cycle, it is reasonable to expect that the sperm survival effect would be most evident during the follicular phase. The current investigation examined whether APM preparations from ampullar regions of the oviduct are less effective than preparations from the isthmus region, and whether sperm survival is more effective in APM preparations derived from follicular phase oviducts than in those derived from luteal phase oviducts.

Attempts were made to characterize the active compound(s) in oviductal APM responsible for supporting the viability of boar spermatozoa. The effect of heat treatment on oviductal APM biological activity was determined. As it is difficult to study membrane proteins in their natural environment (lipid bilayer), a soluble fraction from these membranes was extracted using sodium chloride to facilitate characterization of the active compound(s) in oviductal APM. The salt-extracted soluble APM fraction was biologically active and could support boar sperm viability in vitro. This finding may indicate that the active factor(s) responsible for the maintenance of boar sperm viability is not an integral part of oviductal membranes and is peripherally bound to these membranes.

\section{Materials and Methods}

\section{Oviduct, duodenum and lung tissue preparation}

Pig lung, duodenum and oviduct tissues were donated by Dawkins abattoir (Loughborough). Oviducts (attached to ovaries) were cleaned and washed with cold PBS at the abattoir and transported to the laboratory in PBS on ice. On arrival at the laboratory, oviducts were divided into two groups designated FOL (follicular) and LUT (luteal), on the basis of the appearance of the associated ovaries. Oviducts attached to ovaries containing large follicles (8-12 $\mathrm{mm}$ in diameter) with signs of recent ovulation and no corpora lutea were assigned to the FOL group; those with ovaries containing several corpora lutea, without large follicles were assigned to the LUT group. Oviducts in both groups were trimmed from the ovaries and washed by passing four times through PBS. Each oviduct was divided into three sections. The first, designated as ampulla, was a section between the fimbria and the middle (thicker part) of the oviductal tube. The second section, designated as isthmus, consisted of 1-2 cm of the caudal part of the uterine horn, the uterotubal junction, and up to nearly the middle (thinner part) of the oviductal tube. Finally, a section around the junction of the thin and thick parts of the oviductal tube, approximately $2-3 \mathrm{~cm}$ in length, was excised and discarded to assure differentiation of isthmic and ampullar parts of the oviduct. Each oviduct section (isthmic or ampullar) was processed separately. The sections were opened longitudinally and epithelia were scraped into a Petri dish using a clean glass microscope slide. Scraped tissues collected from approximately 8 12 oviduct sections were collected separately (FOL isthmus, FOL ampulla, LUT isthmus and LUT ampulla) into $20 \mathrm{ml}$ cold PBS and kept on ice. These suspensions were centrifuged for $5 \mathrm{~min}$ at $200 \mathrm{~g}$. The supernatants were discarded and pellets were resuspended in $20 \mathrm{ml}$ buffer 1 (60 mmol mannitol I-1,5 mmol EGTA I-1, $1 \mu \mathrm{mol}$ phenylmethylsulphonylfluoride (PMSF) $\mathrm{I}^{-1}$ and Tris base, $\mathrm{pH}$ 7.4). Suspensions (5 $\mathrm{ml})$ were snap-frozen in liquid nitrogen and stored at $-80^{\circ} \mathrm{C}$ until subsequent use for APM preparation.

Pig lung tissues were finely chopped to a volume of $5 \mathrm{ml}$ to which $20 \mathrm{ml}$ buffer 1 was added. The lung tissue homogenates were snap-frozen in liquid nitrogen and stored at $-80^{\circ} \mathrm{C}$ until subsequent use for APM preparation.

Pig duodenal tissues $(8-12 \mathrm{~cm})$ were opened longitudinally, washed, and epithelia were scraped into a Petri dish using a clean glass microscope slide. Scraped tissues were collected into $20 \mathrm{ml}$ cold PBS and kept on ice. These suspensions were centrifuged for $5 \mathrm{~min}$ at $200 \mathrm{~g}$. The supernatants were discarded and pellets were resuspended in $20 \mathrm{ml}$ buffer $1(\mathrm{pH} \mathrm{7.4)}$. Suspensions $(5 \mathrm{ml})$ were snap-frozen in liquid nitrogen and stored at $-80^{\circ} \mathrm{C}$ until subsequent use for APM preparation. 


\section{APM preparation}

APM preparation from oviduct, lung and duodenum tissue was essentially the same as that described by Smith and Nothnick (1997), with minor modifications. Briefly, tissue homogenates were thawed and homogenized on ice for $1 \mathrm{~min}$ using a small homogenizer (Silverson, Waterside). Aliquots $(200 \mu \mathrm{l})$ of this initial homogenate were snap-frozen in liquid nitrogen and stored at $-80^{\circ} \mathrm{C}$ for subsequent analysis. The homogenate was supplemented with $200 \mu \mathrm{l} 1 \mathrm{~mol} \mathrm{MgCl}_{2} \mathrm{I}^{-1}\left(10 \mathrm{mmol} \mathrm{I}^{-1}\right.$ final concentration) followed by $30 \mathrm{~min}$ incubation on ice. Thereafter the homogenate was centrifuged for $15 \mathrm{~min}$ at $3000 \mathrm{~g}$. The pellet was then discarded and the supernatant was centrifuged for $30 \mathrm{~min}$ at $90000 \mathrm{~g}$. After centrifugation the pellet was resuspended in $20 \mathrm{ml}$ buffer 2 (60 mmol mannitol ${ }^{-1}, 7 \mathrm{mmol} \mathrm{EGTA}^{-1}$ and Tris base, $\mathrm{pH}$ 7.4), with 10 strokes of a Potter S homogenizer. The homogenate was supplemented with $200 \mu \mathrm{l} 1 \mathrm{~mol} \mathrm{MgCl}_{2} \mathrm{I}^{-1}$, incubated on ice for $30 \mathrm{~min}$ (10 $\mathrm{mmol} \mathrm{I}^{-1}$ final concentration) and centrifuged at $3000 \mathrm{~g}$ for $15 \mathrm{~min}$. The pellet was then discarded and the supernatant was centrifuged at $90000 \mathrm{~g}$ for $30 \mathrm{~min}$. After ultracentrifugation the pellet was resuspended in $20 \mathrm{ml}$ modified Tyrode's medium (2 mmol $\mathrm{CaCl}_{2} \mathrm{I}^{-1}, 3.1 \mathrm{mmol}$ $\mathrm{KCl} \mathrm{I}^{-1}, 0.4 \mathrm{mmol} \mathrm{MgCl}_{2} \cdot 6 \mathrm{H}_{2} \mathrm{Ol}^{-1}, 100 \mathrm{mmol} \mathrm{NaCl}$ $\mathrm{I}^{-1}, 25 \mathrm{mmol} \mathrm{NaHCO} 3 \mathrm{I}^{-1}, 0.3 \mathrm{mmol} \mathrm{NaH} \mathrm{PO}_{4} \cdot 2 \mathrm{H}_{2} \mathrm{O}$ $\mathrm{I}^{-1}, 10 \mathrm{mmol}$ Hepes I, $21.6 \mathrm{mmol}$ sodium lactate $\mathrm{I}^{-1}$ and 1 mmol sodium pyruvate $\mathrm{I}^{-1}, \mathrm{pH} 7.4$ ), with 10 strokes of a Potter $\mathrm{S}$ homogenizer. The suspension was centrifuged for $30 \mathrm{~min}$ at $90000 \mathrm{~g}$. The supernatant was then discarded and the pellet was resuspended in $900 \mu \mathrm{l}$ modified Tyrode's medium by aspiration through a $0.9 \times 90 \mathrm{~mm}$ Yale spinal needle (Becton Dickinson, Oxford). This fraction was portioned, snap-frozen in liquid nitrogen and stored at $-80^{\circ} \mathrm{C}$.

\section{Isolation of a soluble fraction from oviductal APM preparations}

The method used was essentially the same as that described by Ohlendieck (1996). An aliquot of oviductal APM preparation obtained from a mixture of FOL, LUT, isthmic and ampullar oviductal tissues was added to an

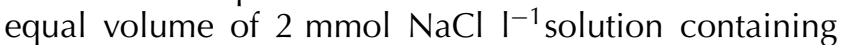
$2 \mu \mathrm{mol} \mathrm{PMSF}{ }^{-1}$. The mixture was incubated at $40^{\circ} \mathrm{C}$ for $30 \mathrm{~min}$ and centrifuged for $1 \mathrm{~h}$ at $100000 \mathrm{~g}$ at $10^{\circ} \mathrm{C}$. The pellet was washed twice with modified Tyrode's medium and stored at $-80^{\circ} \mathrm{C}$. The supernatant containing the salt-extracted fraction was carefully separated and then concentrated using Microcon centrifugal filter devices (Millipore UK Ltd, Watford; 3 kDa cut-off). The concentrated salt-extracted fraction was washed twice with modified Tyrode's medium and stored at $-80^{\circ} \mathrm{C}$.

\section{Protein and $\gamma$-glutamyl transpeptidase activity analysis}

Protein concentrations of initial homogenates, final APM preparations from different tissues, and the salt- extracted fraction obtained from oviductal APM were measured using a protein assay kit (Bio-Rad, Hemel Hempstead). This kit is based on a dye-binding assay, in which the colour of the dye changes differentially, in response to change in protein concentration (Bradford, 1976).

$\gamma$-glutamyl transpeptidase has previously been shown to reside mainly in the APM of polarized epithelial cells (Meister et al., 1976). The activity of $\gamma$-glutamyl transpeptidase in the initial homogenate and in the APM preparations was measured colorimetrically (Naftalin et al., 1969) using diagnostic kit 545 (Sigma, Poole). The assay is based on the transfer of the glutamyl group from L-glutamyl-p-nitroanilide to glycylglycine, catalysed by $\gamma$-glutamyl transpeptidase. The liberated $p$-nitroaniline is diazotized by the addition of sodium nitrite and ammonium sulphamate. The absorbance of the pink azo-dye resulting from the addition of $\mathrm{N}$-(1-napthyl)ethylenediamine, measured at $530-550 \mathrm{~nm}$, is proportional to $\gamma$-glutamyl transpeptidase activity. The extent of enzyme enrichment was expressed as fold increase in $\gamma$-glutamyl transpeptidase activity in the final APM preparations compared with the initial homogenate.

\section{Gel electrophoresis}

Protein separation was performed using the discontinuous buffer system under non-reducing conditions (Laemmli, 1970). Protein from the original homogenate (5 $\mu \mathrm{g}$ ) and purified APM preparations obtained from FOL isthmic, FOL ampullar, LUT isthmic, LUT ampullar and lung tissues were loaded onto SDS-polyacrylamide gels (12\% separation, 5\% stacking). Electrophoresis was carried out on gels for $45 \mathrm{~min}$ at 180 volts using a Bio-Rad modular mini electrophoresis system. The gels were fixed after electrophoresis and then stained with Brilliant Blue G-Colloidal concentrate (Sigma). A digital image was produced from stained gels using an imaging system (Syngene, Cambridge). Protein profiles of the oviductal APM salt-extracted fraction, pellet left after salt extraction and oviductal APM were produced and analysed using the methodology described above.

\section{Semen preparation}

Boar semen, diluted and stored for $24 \mathrm{~h}$ in Beltsville thawing solution (Johnson et al., 1988), was obtained from commercial insemination stations (JSR Healthbred Ltd, Thorpe Willoughby and PIC UK, Abingdon). Semen $(45 \mathrm{ml})$ was washed three times with PBS by centrifugation (600 $\mathrm{g}$ for $10 \mathrm{~min}$ ) and resuspension. After the last centrifugation the supernatant was discarded and the pellet was resuspended in $3 \mathrm{ml}$ modified Tyrode's medium supplemented with $12 \mathrm{mg} \mathrm{ml}^{-1} \mathrm{BSA}, 200 \mathrm{U} \mathrm{ml}^{-1}$ penicillin, $200 \mu \mathrm{g} \mathrm{ml}^{-1}$ streptomycin and $0.5 \mu \mathrm{g} \mathrm{ml} \mathrm{m}^{-1}$ amphotericin B (Life Technologies, Paisley; supplemented Tyrode's medium). Washed semen sample $(1 \mathrm{ml})$ was overlaid with $500 \mu \mathrm{l}$ supplemented Tyrode's 




Fig. 1. The visible protein profile of initial homogenates of pig (lane A) lung, (lane B) follicular phase isthmic and (lane C) follicular phase ampullar tissues and their corresponding apical plasma membrane (APM) preparations (lanes $D, E$ and $F$, respectively). In comparison with the original homogenate, a subset $(77,41$ and $13 \mathrm{kDa}$; arrows, lane B) was diminished and another subset of proteins (45, 37 and $26 \mathrm{kDa}$; arrows, lane E) was enriched after purification of isthmic and ampullar APM preparations. There were distinctive differences in protein profiles of lung and oviductal tissues before and after purification.

medium in a test tube. The tube was placed at a $45^{\circ}$ angle in an incubator held at $39^{\circ} \mathrm{C}$ in a humidified atmosphere saturated with $5 \% \mathrm{CO}_{2}$. After $1 \mathrm{~h}$ the top $0.5 \mathrm{ml}$ of medium containing the swim-up sperm fraction was collected.

Sperm concentration was measured using a counting chamber. Sperm viability was assessed using a combination of ethidium homodimer-1(ETHD-1; Molecular Probes, Leiden) and SYBR-14 (Molecular Probes). One microlitre of $2 \mathrm{mmol}$ ETHD-1 $\mathrm{I}^{-1}$ and $2.5 \mu \mathrm{l}$ $20 \mu \mathrm{mol}$ SYBR-14 $\mathrm{I}^{-1}$ were diluted in $1 \mathrm{ml}$ PBS. An equal volume of the dye mixture was added to the semen sample and incubated for $20 \mathrm{~min}$ at $39^{\circ} \mathrm{C}$. An aliquot of this preparation was placed on a slide and evaluated by epifluorescence microscopy ( $\times 40$ objective). Viable spermatozoa with intact membrane excluding ETHD-1 demonstrated green fluorescence over the nucleus due to SYBR-14 staining. Spermatozoa with disrupted membranes showed red nuclear fluorescence due to ETHD-1 staining (Garner and Johnson, 1995). Two hundred spermatozoa per sample were evaluated by fluorescence microscopy and classified as membrane intact (green) or membrane damaged (red).

\section{Sperm-APM co-incubation}

Swim-up sperm fractions $\left(50 \times 10^{6}\right.$ spermatozoa $\mathrm{ml}^{-1}$ ) in $25 \mu \mathrm{l}$ aliquots were added to $25 \mu \mathrm{l}$ APM (variable concentrations depending on experimental design). Spermatozoa-APM co-incubation droplets were covered with mineral oil and incubated at $39^{\circ} \mathrm{C}, 5 \%$ $\mathrm{CO}_{2}$ for $24 \mathrm{~h}$. After co-incubation, $50 \mu \mathrm{l}$ PBS containing
$20 \mu \mathrm{mol}$ SYBR- $14 \mathrm{I}^{-1}$ and $2 \mu \mathrm{mol}$ ETHD- $1 \mathrm{I}^{-1}$ was added to each droplet and further incubated for $15 \mathrm{~min}$. Thereafter the viability of spermatozoa was assessed as described above.

\section{Statistical analysis}

The data were expressed as mean viability index \pm SEM. Viability index was defined as the percentage of viable spermatozoa after $24 \mathrm{~h}$ incubation in comparison with that of the initial viability of the same semen sample at the beginning of the incubation period. Sperm viability data were tested for normal distribution. ANOVA was used for the statistical analysis of the data. The level of significance was $P \leqslant 0.05$.

\section{Results}

The amount of APM recovered from different tissues after each isolation procedure varied on different days (0.65-1.1, 1.47-4.3, 1.1 and $4.4 \mathrm{mg}$ protein $\mathrm{ml}^{-1}$ for isthmic, ampullar, lung and duodenum APM preparations, respectively). The $\gamma$-glutamyl transpeptidase activity showed an overall increase in APM preparations compared with that of the initial homogenate (five- to 16-fold for isthmic, five- to sevenfold for ampullar, sevenfold for lung and threefold for duodenum).

The electrophoretic profile of initial homogenates and APM preparations of isthmic, ampullar and lung tissues is presented (Fig. 1). The protein profiles of isthmic and ampullar preparations before purification differed at about $40 \mathrm{kDa}$. Protein profiles of isthmic and ampullar APM preparations were similar. Compared with the original homogenate, a subset of proteins (Fig. 1, lane B; 45, 37 and $26 \mathrm{kDa}$ ) was enriched and another subset (Fig. 1, lane E; 77, 41 and $13 \mathrm{kDa}$ ) was diminished after purification of isthmic and ampullar APM preparations. Protein bands at about 28, 31 and 80-116 kDa showed increases or decreases after purification. There were distinctive differences in protein profiles of lung and oviductal tissues before and after purification.

Protein profiles of the oviductal APM preparations, oviductal APM salt-extracted fraction and pellet left after the salt extraction are presented (Fig. 2). The protein profile of oviductal APM and pellet left after the salt extraction were similar. The protein profile of the saltextracted fraction showed enrichment for most of the proteins visible in the profile, particularly for proteins of 41, 38, 18 and $13.5 \mathrm{kDa}$ (Fig. 2, lane B).

The overall viability of spermatozoa after swim-up and at the start of co-incubation was $68 \% \pm 3$ (mean \pm SEM). Generally, after swim-up procedures, most recovered samples showed different extents of head-to-head agglutination. Agglutination was particularly apparent after incubation in the presence of oviductal APM preparations. In general, a couple or a maximum of 10-20 spermatozoa were agglutinated. This head-to-head agglutination 


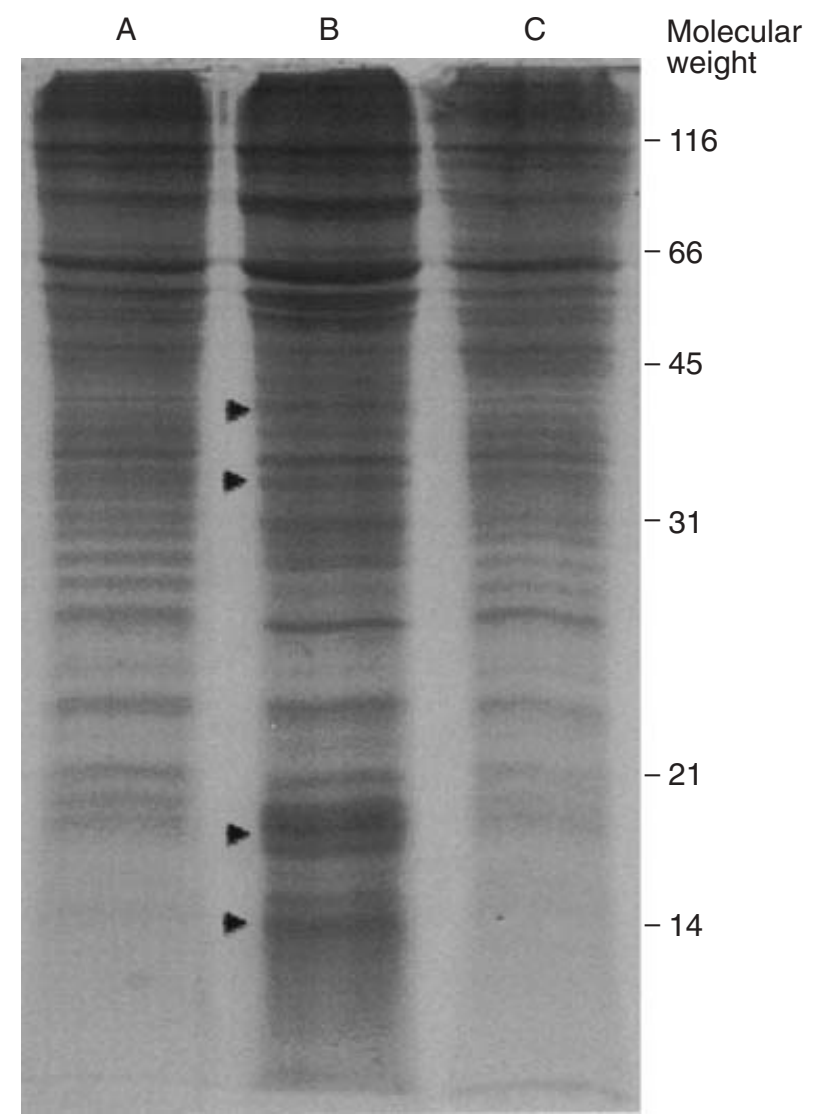

Fig. 2. The visible protein profile of pig (lane A) oviductal apical plasma membrane (APM) preparations, (lane B) oviductal APM saltextracted fraction and (lane C) pellet left after salt extraction. The protein profile of the salt-extracted fraction showed enrichment for most proteins visible in the profile, particularly for proteins of 41 , 38, 18 and $13.5 \mathrm{kDa}$ (arrows, lane B).

was not induced in samples incubated in the presence of the soluble fraction of oviductal APM, lung APM or control. All viability data were expressed as percentage of viable spermatozoa after $24 \mathrm{~h}$ incubation in comparison with that of the initial viability of the same semen sample at the beginning of the incubation period (viability index) to allow a uniform comparison between different samples and experiments.

Determination of the dose-response effect of $F O L$ isthmic APM preparations on the maintenance of boar spermatozoa viability in vitro

The viability index of boar spermatozoa incubated in the presence of different concentrations of $\mathrm{FOL}$ isthmic APM preparations $\left(100,200\right.$ and $400 \mu \mathrm{g} \mathrm{ml}^{-1}$ ) was higher than that of the control (without APM) after $24 \mathrm{~h}$ incubation (Fig. 3). Spermatozoa from six different boars were used in the experiments (one ejaculate per boar). There was a significant concentration effect on the longevity of boar spermatozoa $(P<0.01)$. Sperm viability was increased by about $10 \%$ with $100 \mu \mathrm{g} \mathrm{ml}^{-1}$ APM over

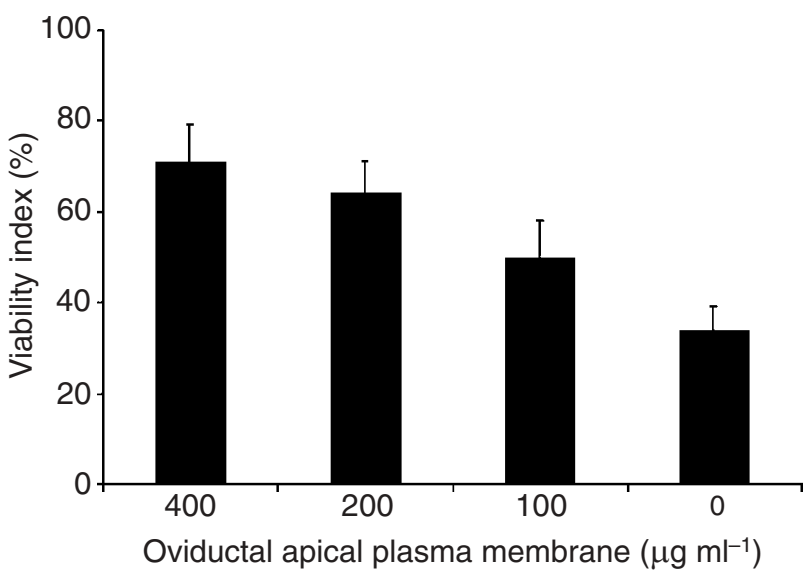

Fig. 3. Viability index (mean \pm SEM) of boar spermatozoa incubated for $24 \mathrm{~h}$ with different concentrations of oviductal apical plasma membrane preparations. There was a significant concentration effect on longevity of boar spermatozoa $(P<0.01)$.

that of control, and was almost doubled by incubating with $400 \mu \mathrm{g} \mathrm{ml}^{-1}$ APM.

Specificity of the FOL isthmic APM preparations effect on the longevity of boar spermatozoa in vitro

The viability index of boar spermatozoa incubated for $24 \mathrm{~h}$ in supplemented Tyrode's medium (control) was significantly $(P \leqslant 0.005)$ lower than that incubated with FOL isthmic APM preparations $\left(200 \mu \mathrm{g} \mathrm{ml}^{-1} ; 31 \% \pm 9\right.$ and $60 \% \pm 11$, respectively). However, the viability index of spermatozoa incubated with lung APM preparations $\left(200 \mu \mathrm{g} \mathrm{ml}^{-1} ; 39 \% \pm 7\right)$ was not different from that of the control and it was significantly $(P \leqslant 0.05)$ lower than that incubated with FOL isthmic APM preparations. Spermatozoa from six different boars were used in the experiments (one ejaculate per boar).

\section{Effect of oviductal APM origin on the maintenance of boar sperm viability in vitro}

There was no significant difference between the viability index of spermatozoa co-incubated for $24 \mathrm{~h}$ with APM preparations obtained from FOL phase isthmic $\left(200 \mu \mathrm{g} \mathrm{ml}^{-1}\right)$ or FOL phase ampullar $\left(200 \mu \mathrm{g} \mathrm{ml}^{-1}\right)$ tissues $(76 \% \pm 5$ and $74 \% \pm 16$, respectively). However, there was a significant decrease in the viability of spermatozoa in control $(39 \% \pm 6)$ compared with that incubated with either oviductal APM preparation $(P \leqslant 0.001)$. Spermatozoa from six different boars were used in the experiments (one ejaculate per boar).

\section{Effect of FOL and LUT phase oviductal APM}

preparations on the maintenance of boar sperm viability in vitro

As no difference was seen between isthmic and ampullar preparations in the previous experiment, equal 


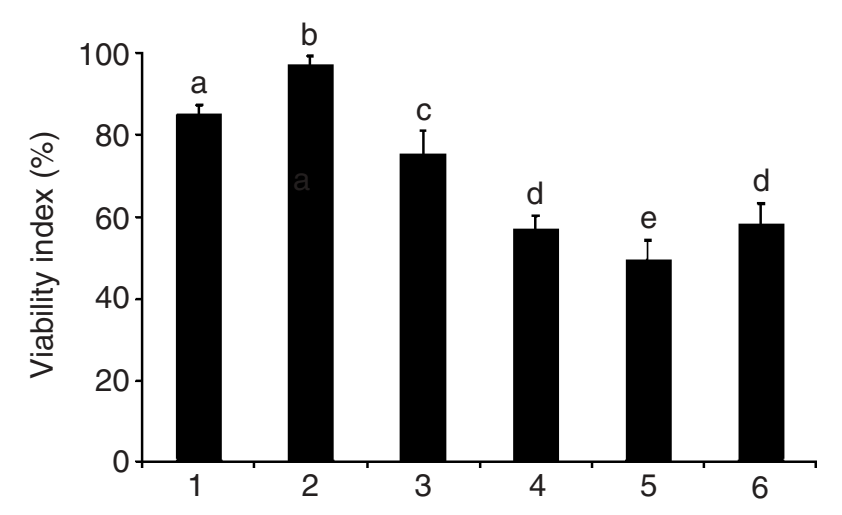

Fig. 4. Viability index (mean $\pm S E M$ ) of boar spermatozoa incubated for $24 \mathrm{~h}$ with (1) oviductal apical plasma membrane (APM) preparation; (2) oviductal APM salt-extracted fraction; (3) pellet left after salt extraction; (4) lung APM preparation; (5) duodenum APM preparation; and (6) control (medium only). Experiments were carried out using twelve different ejaculates. Means with different letters are significantly different $(P \leqslant 0.05)$.

amounts of FOL isthmic and FOL ampullar APM preparations were mixed to provide a FOL oviductal APM preparation. In the case of LUT APM preparation, this was achieved by mixing equal amounts of LUT isthmic and LUT ampullar APM preparations. Oviductal APM preparations obtained from sows in the FOL $(200 \mu \mathrm{g}$ $\left.\mathrm{ml}^{-1}\right)$ and LUT $\left(200 \mu \mathrm{g} \mathrm{ml}^{-1}\right)$ stages of the reproductive cycle maintained boar sperm viability in vitro to the same extent ( $82 \pm 6$ and $84 \pm 6$, respectively). The viability of spermatozoa co-incubated with these preparations was significantly $(P \leqslant 0.0001)$ higher than the control $(49 \pm 9)$ at the end of the co-incubation period (24 h). Spermatozoa from eight different boars were used in the experiments (one ejaculate per boar).

\section{Effect of heat treatment on the ability of APM preparations to maintain boar sperm viability in vitro}

As no difference was seen in the previous experiment between FOL and LUT phase oviductal preparations, a mixture of both preparations was used in the following experiments. An aliquot of oviductal APM was incubated at $100^{\circ} \mathrm{C}$ for $20 \mathrm{~min}$. Heat treatment of oviductal APM preparations significantly $(P<0.04)$ reduced the viability enhancing effect of the oviductal APM preparations $\left(59 \pm 5,78 \pm 9\right.$ and $65 \pm 5$ for $200 \mu \mathrm{g} \mathrm{ml}^{-1}$ heat-treated APM, $200 \mu \mathrm{g} \mathrm{ml}^{-1}$ non-heat-treated APM and control, respectively). Spermatozoa from eight different boars were used in the experiments (one ejaculate per boar).

\section{Determination of the effect of oviductal APM salt-extracted fraction on the maintenance of boar sperm viability in vitro}

The viability indices of spermatozoa co-incubated with the salt-extracted fraction $\left(200 \mu \mathrm{g} \mathrm{ml}^{-1}\right)$, the pellet left after salt extraction $\left(200 \mu \mathrm{g} \mathrm{ml}^{-1}\right)$ and oviductal APM $\left(200 \mu \mathrm{g} \mathrm{m}^{-1}\right)$ were all significantly $(P<0.05)$ higher than that of spermatozoa incubated with lung $(200 \mu \mathrm{g}$ $\mathrm{ml}^{-1}$ ), duodenum $\left(200 \mu \mathrm{g} \mathrm{ml}^{-1}\right.$ ) or control (medium only; Fig. 4). The capacity of the salt-extracted fraction in maintaining sperm viability was significantly higher than that of the pellet left after salt extraction $(P<0.0001)$ and oviductal APM $(P<0.004)$. The capacity of the pellet left after salt extraction in maintaining sperm viability was also lower than that of oviductal APM $(P<0.01)$. Spermatozoa from twelve different boars were used in the experiments (one ejaculate per boar).

\section{Discussion}

Co-culture with oviductal epithelial cells in vitro improves the survival of spermatozoa from a number of species including rabbits (Li et al., 1990), cows (Ellington et al., 1991; Pollard et al., 1991), sheep (Gutierrez et al., 1993), horses (Ellington et al., 1991; Thomas et al., 1994), pigs (Fazeli et al., 1997) and humans (Kervancioglu et al., 1994). It seems that this is a widespread characteristic of oviductal cells. However, the mechanism by which oviductal cells maintain sperm viability is unknown. Both oviductal secretory products (ljaz et al., 1994; Yeung et al., 1994) and direct membrane contact between spermatozoa and oviductal epithelial cell membranes (Dobrinski et al., 1997; Smith and Nothnick, 1997) have been reported to maintain sperm viability. The current investigation was not principally aimed at determining the mechanism underlying the maintenance of sperm viability by oviductal cells. However, the results clearly demonstrate that APM obtained from pig oviductal epithelial cells are capable of improving boar sperm viability in vitro.

APM preparations have been made from rabbit (Smith and Nothnick, 1997), mare (Dobrinski et al., 1997) and human (Murray and Smith, 1997) oviductal tissues. The method of choice in these studies was differential precipitation, a very simple and effective technique. However, because lysosomal membranes also contain some acidic glycoproteins and may co-precipitate with the APM, the possibility of the final fraction containing other cellular membranes cannot be ruled out. The present study, and the studies of Dobrinski et al. (1997), Murray and Smith (1997) and Smith and Nothnick (1997) used $\gamma$-glutamyl transpeptidase as a marker enzyme for investigating the enrichment of APM in the final preparations. The $\gamma$-glutamyl transpeptidase activity increased several-fold in the final preparation compared with that in the initial homogenates. This demonstrated the success of the method used to isolate APM preparations from the initial homogenates. In addition, there were distinct differences in the protein profile of APM preparations compared with that of original homogenates. Three protein bands diminished and three bands were enriched 
in APM preparations compared with that of the initial oviductal homogenates. This result provides another indication that the differential precipitation technique resulted in separation of a sub-fraction of the original homogenate.

In the present investigation no beneficial effect on the maintenance of boar sperm viability in vitro was observed by co-incubating boar spermatozoa with lung and duodenum APM preparations. These findings support the failure of previous investigators (Smith and Nothnick, 1997) to find significant effects of non-reproductive tissue (kidney) APM preparations on rabbit sperm viability. However, Dobrinski et al. (1997) found that kidney APM preparations have a moderately beneficial effect on equine sperm viability. In the same study only oviductal APM preparations were capable of inducing a delay in capacitation and maintenance of low $\left[\mathrm{Ca}^{2+}\right]_{i}$ and not those APM preparations obtained from kidney. Thus, non-reproductive tissue APM may have some beneficial effect on stallion spermatozoa, but this effect is not completely comparable to that of oviductal APM tissue.

To the best of the authors' knowledge, this is the first report describing the sperm viability maintenance effect of oviductal APM in pigs. Furthermore, the findings indicate a distinct dose-response effect of these preparations on the maintenance of boar sperm viability and imply that the isthmic APM interaction with boar spermatozoa follows the kinetics of an enzyme substrate reaction, mediated by a receptor-ligand like interaction.

Given the functions of the oviductal reservoir, such as transport and selection of spermatozoa in the female reproductive tract, maintenance of sperm viability and regulation of capacitation, functional differences between isthmic and ampullar regions of the oviduct would be expected. However, the current investigation found no significant difference in the ability of APM obtained from isthmic or ampullar regions of pig oviduct to maintain boar sperm viability in vitro. These findings are in agreement with observations that oviductal epithelial cells obtained from both isthmic and ampullar regions of the oviduct maintain boar sperm viability (Fazeli et al., 1997) and induce boar sperm capacitation (Fazeli et al., 1999) to the same extent. Furthermore, Smith and Nothnick (1997) demonstrated that preparations of APM from whole rabbit oviducts, which included isthmus and ampulla, prolong buck sperm viability. Murray and Smith (1997) also prepared APM from both isthmic and ampullar sections of human Fallopian tube. Thus, the membranes from the ampullar region may have contributed to the effects they observed.

In the present investigation, both FOL phase and LUT phase oviductal APM supported the viability of boar spermatozoa in vitro. In another study using oviductal APM, only those obtained from oviducts at the periovulatory stage of the reproductive cycle, and not at the preovulatory or anovulatory stages of the cycle, were capable of maintaining buck sperm viability
(Smith and Nothnick, 1997). This may be related to species differences in the biology of the sperm-oviduct interaction. Ovulation in rabbits is induced by mating and spermatozoa reside in the female reproductive tract for 10-12 $\mathrm{h}$ before eggs are released (Overstreet and Adams, 1971; Overstreet and Cooper, 1975).

Evidence presented in the current investigation that heat treatment of oviductal APM preparations abolished biological activity of the preparations indicates that proteins in these membrane fractions are the active factor(s) responsible for oviductal APM biological activity. Proteins unfold or denature under various conditions and thermal energy from heat can break the weak bonds, destabilizing protein native conformation. Denatured proteins lose both their compact conformation and biological activity.

Proteins are associated with biological membranes in different ways. Some proteins that do not extend into the hydrophobic interior of the lipid bilayer at all are bound to one or the other face of biomembranes by non-covalent interactions with other membrane proteins. Many of these proteins can be released from the membrane by relatively gentle extraction procedures, such as exposure to solutions of very high or low ionic strength or extreme $\mathrm{pH}$, which interfere with protein-protein interactions but leave the lipid bilayer intact; these proteins are referred to operationally as peripheral membrane proteins (Ohlendieck, 1996). By contrast, transmembrane proteins, many proteins held in the bilayer by lipid groups, and some other tightly bound proteins cannot be released in these ways and therefore are called integral membrane proteins. In the current investigation, treating the membranes with a high ionic-strength salt solution resulted in a solubilized fraction of oviductal APM. As expected, there were distinct differences between the visible protein profile of this soluble fraction compared with the original APM or the membrane protein fractions (pellet) left after the salt extraction. As biological activity was still present in the oviductal APM salt-extracted fraction, it appears that active protein(s) responsible for the maintenance of sperm viability by oviductal APM belongs to the peripheral membrane protein category. Apart from its physiological significance, this finding may have important technical implications regarding future strategies for purification and characterization of active protein(s) responsible for maintaining boar sperm viability by oviductal APM preparations. Although most proteins present in the salt-extracted fraction should have originated from oviductal APM, one cannot rule out the existence of peripheral proteins from other organelle membranes such as endoplasmic reticulum, lysosomes and mitochondria. In addition, both the extracellular and intracellular sides of membranes had been exposed to salt extraction. This probably resulted in extraction of both extracellular and intracellular peripheral membranebound proteins. 
Three proteins belonging to the chaperone family (heat shock protein 60, glucose-regulated protein 78 and a protein with high similarity to a $60 \mathrm{kDa}$ protein disulphide isomerase) have been found to bind to the sperm surface after co-incubating bull spermatozoa with ${ }^{35}$ S-radiolabelled oviductal APM (Boilard et al., 2001). Molecular chaperones facilitate protein folding (Agard, 1993) by binding to exposed hydrophobic regions. The chaperone repairs those regions of a protein that are likely to have misfolded, changing their structure in a way that gives the protein another chance to fold. It would be interesting to study the presence of chaperones in the saltextracted fraction prepared in the current investigation.

In conclusion, the current investigation has demonstrated the ability of oviductal APM to support and prolong boar sperm viability in a dose-dependent manner. This effect is limited to APM obtained from oviductal tissue. The origin of APM, whether from isthmic or ampullar regions of the oviduct, and the cycle stage of animals from which oviductal APM is obtained, do not seem to influence the ability of APM to maintain boar sperm viability. Furthermore, the present study determined that a soluble oviductal APM salt-extracted fraction is biologically active and can support boar sperm viability in vitro. This finding may indicate that the active factor(s) responsible for the maintenance of boar sperm viability is not an integral part of oviductal membranes and is peripherally bound to these membranes. It would be interesting to investigate whether the active factors in pig oviduct capable of maintaining boar sperm viability can also prolong the viability of spermatozoa from other species. Future efforts will be directed towards characterization of the active factors in the soluble fraction obtained from oviductal APM and the possibility that carbohydrates are involved in mediation of maintenance of sperm viability by the oviduct.

The authors thank A. G. Hartley for technical assistance, Dawkins abattoir for donation of pig oviductal tissue, and JSR Healthbred Ltd and PIC UK for donation of boar semen samples. This study was supported by a grant from the Department for Environment, Food and Rural Affairs (UK).

\section{References}

Abe H, Sendai Y, Satoh T and Hoshi H (1995a) Secretory products of bovine oviductal epithelial cells support the viability and motility of bovine spermatozoa in culture in vitro. Journal of Experimental Zoology 272 $54-61$

Abe H, Sendai Y, Satoh T and Hoshi H (1995b) Bovine oviduct-specific glycoprotein: a potent factor for maintenance of viability and motility of bovine spermatozoa in vitro. Molecular Reproduction and Development 42 226-232

Agard DA (1993) To fold or not to fold Science 260 1903-1904

Boilard M, Reyes-Moreno C and Sirard MA (2001) Binding of chaperonins to bovine spermatozoa by direct contact to apical plasma membrane of oviduct epithelial cells Biology of Reproduction $\mathbf{6 4} 112$
Bradford MM (1976) A rapid and sensitive method for the quantitation of microgram quantities of protein utilizing the principle of protein-dye binding Analytical Biochemistry 72 248-254

DeMott RP, Lefebvre R and Suarez SS (1995) Carbohydrates mediate the adherence of hamster sperm to oviductal epithelium Biology of Reproduction 52 1395-1403

Dobrinski I, Smith TT, Suarez SS and Ball BA (1997) Membrane contact with oviductal epithelium modulates the intracellular calcium concentration of equine spermatozoa in vitro. Biology of Reproduction 56 861-869

Ellington JE, Padilla AW, Vredenburgh WL, Dougherty EP and Foote RH (1991) Behavior of bull spermatozoa in bovine uterine tube epithelial cell coculture - an in vitro model for studying the cell interactions of reproduction Theriogenology 35 977-989

Ellington JE, Ball BA, Blue BJ and Wilker CE (1993) Capacitationlike membrane changes and prolonged viability in vitro of equine spermatozoa cultured with uterine tube epithelial cells American Journal of Veterinary Research $\mathbf{5 4}$ 1505-1510

Fazeli A, Hage WJ, Cheng FP, Voorhout WF, Marks A, Bevers MM and Colenbrander B (1997) Acrosome-intact boar spermatozoa initiate binding to the homologous zona pellucida in vitro. Biology of Reproduction 56 430-438

Fazeli A, Duncan AE, Watson PF and Holt WV (1999) Sperm-oviduct interaction: induction of capacitation and preferential binding of uncapacitated spermatozoa to oviductal epithelial cells in porcine species Biology of Reproduction 60 879-886

Flechon JE and Hunter RH (1981) Distribution of spermatozoa in the uterotubal junction and isthmus of pigs, and their relationship with the luminal epithelium after mating: a scanning electron microscope study Tissue and Cell 13 127-139

Garner DL and Johnson LA (1995) Viability assessment of mammalian sperm using SYBR-14 and propidium iodide Biology of Reproduction 53276 284

Green CE, Bredl J, Holt WV, Watson PF and Fazeli A (2001) Carbohydrate mediation of boar sperm binding to oviductal epithelial cells in vitro. Reproduction 122 305-315

Gutierrez A, Garde J, Garcia-Artiga C and Vazquez I (1993) Ram spermatozoa cocultured with epithelial cell monolayers: an in vitro model for the study of capacitation and the acrosome reaction Molecular Reproduction and Development 36 338-345

Hunter RH (1981) Sperm transport and reservoirs in the pig oviduct in relation to the time of ovulation Journal of Reproduction and Fertility $\mathbf{6 3}$ 109-117

Hunter RH (1984) Pre-ovulatory arrest and peri-ovulatory redistribution of competent spermatozoa in the isthmus of the pig oviduct Journal of Reproduction and Fertility 72 203-211

Hunter RH and Nichol R (1983) Transport of spermatozoa in the sheep oviduct: preovulatory sequestering of cells in the caudal isthmus Journal of Experimental Zoology 228 121-128

Hunter RH, Flechon B and Flechon JE (1991) Distribution, morphology and epithelial interactions of bovine spermatozoa in the oviduct before and after ovulation: a scanning electron microscope study Tissue and Cell 23 641-656

ljaz A, Lambert RD and Sirard MA (1994) In vitro-cultured bovine granulosa and oviductal cells secrete sperm motility-maintaining factor(s) Molecular Reproduction and Development 37 54-60

Johnson LA, Aalbers JG and Grooten HJG (1988) Artificial insemination of swine - fecundity of boar semen stored in Beltsville Ts (Bts), Modified modena $(\mathrm{Mm})$, or Mr-a and inseminated on 1, 3 and 4 days after collection Reproduction in Domestic Animals - Zuchthygiene 23 49-55

Kawakami E, Hori T and Tsutsui T (1998) Induction of dog sperm capacitation by oviductal fluid Journal of Veterinary Medical Science 60 197-202

Kawakami E, Arai T, Oishi I, Hori T and Tsutsui T (2000) Induction of dog sperm capacitation by glycosaminoglycans and glycosaminoglycan amounts of oviductal and uterine fluids in bitches Journal of Veterinary Medical Science 62 65-68

Kervancioglu ME, Djahanbakhch O and Aitken RJ (1994) Epithelial cell coculture and the induction of sperm capacitation Fertility and Sterility 61 1103-1108 
Laemmli UK (1970) Cleavage of structural proteins during the assembly of the head of bacteriophage T4 Nature 227 680-685

Lapointe S and Sirard MA (1996) Importance of calcium for the binding of oviductal fluid proteins to the membranes of bovine spermatozoa Molecular Reproduction and Development 44 234-240

Lapointe S and Sirard MA (1998) Catalase and oviductal fluid reverse the decreased motility of bovine sperm in culture medium containing specific amino acids Journal of Andrology 19 31-36

Li J, Carney E, Chen Y-Q, Yang X and Foote RH (1990) Rabbit oviduct epithelial cell culture as a possible model for capacitating sperm Theriogenology $\mathbf{3 0} 274$

McNutt TL, Olds-Clarke P, Way AL, Suarez SS and Killian GJ (1994) Effect of follicular or oviductal fluids on movement characteristics of bovine sperm during capacitation in vitro. Journal of Andrology 15 328-336

Martus NS, Verhage HG, Mavrogianis PA and Thibodeaux JK (1998) Enhancement of bovine oocyte fertilization in vitro with a bovine oviductal specific glycoprotein Journal of Reproduction and Fertility 113 323-329

Meister A, Tate SS and Ross LL (1976) Membrane-bound $\gamma$-glutamyl transpeptidase. In The Enzymes of Biological Membranes pp 315-328 Ed. AN Martonosi. Plenum Press, New York

Motta P and Van Blerkom J (1975) A scanning electron microscopic study of rabbit spermatozoa in the female reproductive tract following coitus Cell and Tissue Research $16329-44$

Murray SC and Smith TT (1997) Sperm interaction with Fallopian tube apical membrane enhances sperm motility and delays capacitation Fertility and Sterility 68 351-357

Naftalin L, Sexton M, Whitaker JF and Tracey D (1969) A routine procedure for estimating serum gamma-glutamyltranspeptidase activity Clinica Chimica Acta 26 293-296

Ohlendieck K (1996) Extraction of membrane proteins. In Methods in Molecular Biology pp 293-304 Ed. S Doonan. Human Press Inc., Totawa, NJ

Overstreet JW and Adams CE (1971) Mechanisms of selective fertilization in the rabbit: sperm transport and viability Journal of Reproduction and Fertility 26 219-231

Overstreet JW and Cooper GW (1975) Reduced sperm motility in the isthmus of the rabbit oviduct Nature 258 718-719

Pollard JW, Plante C, King WA, Hansen PJ, Betteridge KJ and Suarez SS (1991) Fertilizing capacity of bovine sperm may be maintained by binding of oviductal epithelial cells Biology of Reproduction $\mathbf{4 4}$ 102-107

Rodriguez C and Killian G (1998) Identification of ampullary and isthmic oviductal fluid proteins that associate with the bovine sperm membrane Animal Reproduction Science 54 1-12

Smith TT and Nothnick WB (1997) Role of direct contact between spermatozoa and oviductal epithelial cells in maintaining rabbit sperm viability Biology of Reproduction 56 83-89

Smith TT and Yanagimachi R (1990) The viability of hamster spermatozoa stored in the isthmus of the oviduct: the importance of sperm-epithelium contact for sperm survival Biology of Reproduction 42 450-457

Smith TT and Yanagimachi R (1991) Attachment and release of spermatozoa from the caudal isthmus of the hamster oviduct Journal of Reproduction and Fertility 91 567-573

Smith TT, Koyanagi F and Yanagimachi R (1987) Distribution and number of spermatozoa in the oviduct of the golden hamster after natural mating and artificial insemination Biology of Reproduction 37 225-234

Suarez SS (1987) Sperm transport and motility in the mouse oviduct: observations in situ. Biology of Reproduction 36 203-210

Suarez S, Redfern K, Raynor P, Martin F and Phillips DM (1991) Attachment of boar sperm to mucosal explants of oviduct in vitro: possible role in formation of a sperm reservoir Biology of Reproduction $\mathbf{4 4}$ 998-1004

Thomas PG, Ball BA, Miller PG, Brinsko SP and Southwood L (1994) A subpopulation of morphologically normal, motile spermatozoa attach to equine oviductal epithelial cell monolayers Biology of Reproduction 51 303-309

Yanagimachi R (1994) Mammalian fertilization. In The Physiology of Reproduction pp 189-317 Eds E Knobil and JD Neill. Raven Press, New York

Yeung WS, Ng VK, Lau EY and Ho PC (1994) Human oviductal cells and their conditioned medium maintain the motility and hyperactivation of human spermatozoa in vitro. Human Reproduction 9 656-660

Received 18 September 2002.

First decision 21 November 2002.

Revised manuscript received 17 December 2002.

Accepted 13 January 2003. 